\title{
Schistosomiasis: from established diagnostic assays to emerging micro/nanotechnology-based rapid field testing for clinical management and epidemiology
}

Maurice Mutro Nigo ${ }^{1,4}$, Georgette B. Salieb-Beugelaar ${ }^{1,2,4}$, Manuel Battegay ${ }^{1,4}$, Peter Odermatt ${ }^{3,4}$, Patrick Hunziker ${ }^{1,2,4 *}$

University Hospital of Basel ${ }^{l}$, Switzerland, CLINAM Foundation' ${ }^{2}$ Basel, Switzerland,

Swiss Tropical and Public Health Institute ${ }^{3}$,Basel, Switzerland, University of Basel ${ }^{4}$,Basel, Switzerland

Submitted: December 5, 2019

Published: December 19, 2019

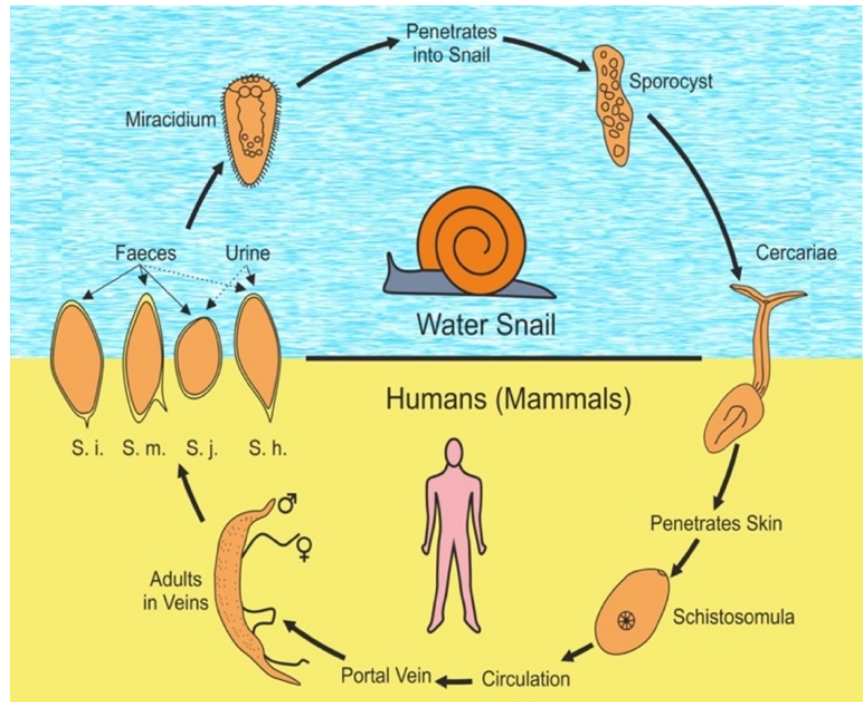

Caption: Schistosoma mansoni life cycle (1) Paired adult worms (female is thin, male is bigger), (2) Eggs (see note below), (3) Ciliated miracidium, (4) Biomphalaria intermediate host snail, (5) Sporocyst, (6) Cercariae, the infective stage, and (7) Schistosomula, the young parasite.

\section{Abstract}

Schistosomiasis is a neglected invasive worm disease with a huge disease burden in developing countries, particularly in children, and is seen increasingly in non-endemic regions through transfer by travellers, expatriates, and refugees. Undetected and untreated infections may be responsible for the persistence of transmission. Rapid and accurate diagnosis is the key to treatment and control. So far, parasitological detection methods remain the cornerstone of Schistosoma infection diagnosis in endemic regions, but conventional tests have limited sensitivity, in particular in low-grade infection. Recent advances contribute to improved detection in clinical and field settings. The recent progress in micro- and nanotechnologies opens a road by enabling the design of new miniaturized point-of-care devices and analytical platforms, which can be used for the rapid detection of these infections. This review starts with an overview of currently available laboratory tests and their performance and then discusses emerging rapid and micro/nanotechnologies-based tools. The epidemiological and clinical setting of testing is then discussed as an important determinant for the selection of the best analytical strategy in patients suspected to suffer from Schistosoma infection. Finally, it discusses the potential role of advanced technologies in the setting near to disease eradication is examined.

Keywords: schistosomiasis, rapid, accurate, POC, diagnosis, immunoassays, PCR, LAMP, microfluidic, microarray.

* Corresponding author: Patrick Hunziker, patrick.hunziker@swissnano.org, University Hospital Basel, Switzerland

Prnano.com, https://doi.org/10.33218/prnano3(1).191205.1 


\section{Purpose and Rationale:}

The limitations of available diagnostic tests for schistosomiasis contribute to our current failure in disease control and eradication of this important poverty disease. This paper therefore aims at delineating specific requirements and desirable characteristics for a new generation of diagnostics based on the micro- and nanotechnologies, driven by the conviction that new technologies should benefit all segments of humankind, including the poorest.

\section{Introduction}

Schistosomiasis is one of the most prevalent and widespread [1] parasitic neglected tropical diseases in the world. It is caused by fluke worms of the genus Schistosoma and affects humans and various other animals [2,3]. The 6 species involved in human infections are $S$. mansoni, S. haematobium, S. japonicum, $S$. mekongi, S. guinensii and S. intercalatum. The respective distribution, the population at risk and the main clinical manifestations are summarized in Table 1.3. Infection starts when cercariae released by snails penetrate through the skin exposed to infested water [4]. More details on the life cycle are given in Figure 1. Schistosomiasis affects 221 million people where children between 5 and 14 years of age which represents $45.8 \%$ of the affected patients [5] and puts at risk 800 million people in 74 countries worldwide [6, 7]. In sub-Saharan Africa, the number of affected people is 54 million and 393 million are at risk.[7] Worldwide, the disease kills about 300,000 patients annually [8] and results in approximately 25 million disability adjusted life years lost [9] despite the implementation of control measures [10].

Selective therapy of school children or mass drug administration (MDA) are widely used to control schistosomiasis, but fail to prevent rapid reinfection in endemic areas [8]. A substantial decrease in morbidity and mortality is observed in some of these areas, but the disease continues to spread to new geographic regions. It is increasingly imported into non- or low-endemic countries due to the increased migration of the human population (e.g., refugees, international tourism, and/or international projects) and additionally, environmental changes that result from development of water resources and population growth and migration can facilitate the spread of schistosomiasis [11, 12]. Diagnostics address both the individual and population needs. At the individual level, they first can detect disease and identify patients at risk of severe disease, which will permit good clinical decision making and good case management.

The use of diagnostics also supports (1) the detection and prevention of drug resistance, (2) the surveillance of a disease, and (3) the assessment of the efficacy of drugs and vaccines in clinical studies [13]. Rapid and accurate diagnosis of schistosomiasis is a challenge [14]. It remains a key requirement for treatment and control [15-19]. There is still a need to determine the existence of infection more simply and reliably, both, in hospital settings where severe pathological effects are suspected, as well as in the field [20,21].

The current diagnosis of schistosome infection is based mainly on clinical symptoms, and therefore low-level and chronic or asymptomatic/atypical infections are often missed $[22,23]$. Various procedures to detect this infection have been validated and include direct parasitological techniques, immunologic methods, and molecular approaches [24]. The sensitivity of parasitological tests decreases when parasite egg numbers are low or eggs are absent [25] and specificity of rapid diagnostic tests (RDTs) is variable [24]. Routine serological tests such as enzyme-linked immunosorbent assay (ELISA) have good sensitivity but may cross-react with intestinal nematodes [26]. Methods based on the amplification of a highly repeated deoxyribonucleic acid (DNA) sequence by polymerase chain reaction (PCR) in fecal and serum human samples [27] show high sensitivity, high specificity, and good predictive value. Yet, the test cost and the need for specific laboratory equipment and conditions limit the use of these assays in many laboratories. The real-time polymerase chain reaction (RT-PCR) method, in spite of its high sensitivity and specificity [24], has remained only as a confirmatory diagnostic test, since it is intensive work and expensive. To reduce the costs loop mediated isothermal amplification (LAMP) of DNA was developed. Both LAMP and microarray methods have been tested and so far these methods promise to be excellent tools in epidemiological and clinical screenings 
[1] but, the diagnostic performance of these techniques in areas with different schistosomiasis prevalence is so variable that it is difficult to declare a "gold standard" test [28, 29]. Also, the amplification mechanism of LAMP may easily lead to carryover contamination and therefore false-positive results.

The rapid evolution of micro- and nanofabrication technologies opens a door for the development and evaluation of new methods and tools for the diagnosis of schistosome infection. In this chapter we will first present the currently available diagnostics, followed by the latest developments in the field and end with a discussion. With a view on clinical application, the value of diagnostic tests for patients in different epidemiological scenarios is discussed. As a comprehensive review of the huge body of work that is being performed is outside the scope of this paper, we aim to provide an update of current relevant achievements in the field. The cited articles are collected by cross-referencing online keyword searches ("Schistosoma diagnostics methods" "Schistosomisis" "S. mansoni $S$. haematobium S. japonicum" "POC") in citation and database searching on Pubmed from January 1990 to November 2019. The works perceived as most important are exemplarily presented in this review. The emphasis of literature citations is on the development of point-of-care diagnostics for parasitic infections.

\section{Established diagnostic assays for schistosomiasis}

Current laboratory tests for schistosome infection are based on direct parasitological detection, the detection of circulating antigens and/or specific antibodies, and molecular methods. More detailed information can be found in focused literature [13, 30]. As the background of evaluation for emerging and future test modalities, the current clinically available tests are summarized in the next paragraphs.

Microscopy: direct detection of parasite eggs

The reference method for the laboratory diagnosis of a schistosome infection is parasite egg detection in the infected individual's stool, urine, or tissues [31, 32]. Such parasitological detection (PD) is widely used because it is relatively efficacious and moderately cost-effective for case management, screening or surveillance. The success of control measures against schistosomiasis has been difficult to determine because the sensitivity of PD decreases when there is no egg excretion, or it diminishes, principally in areas of low endemicity [25]

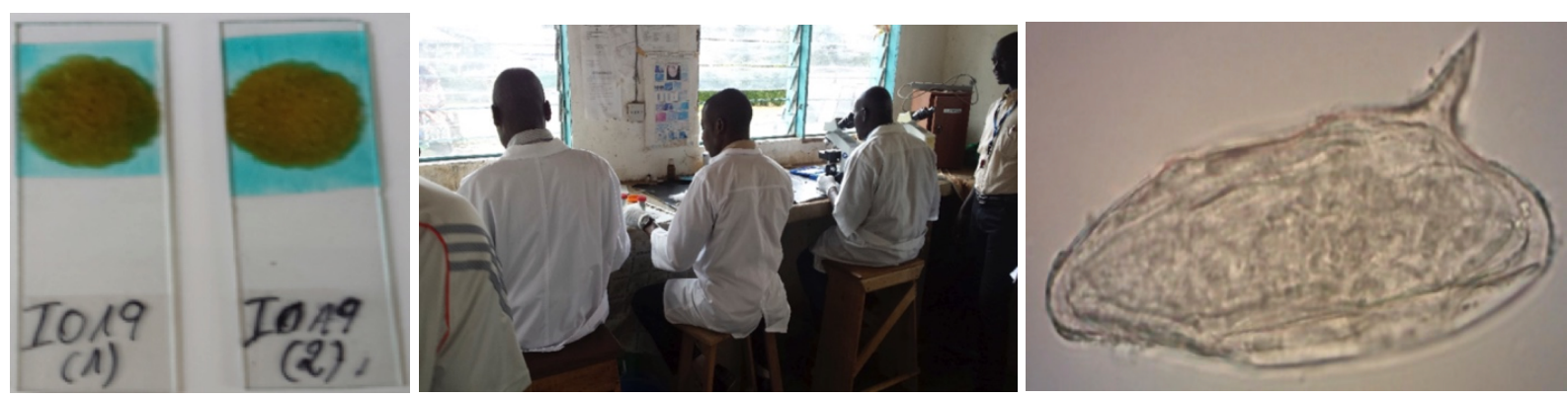

Figure 1: Current diagnostics of intestinal schistosomiasis relies on the microscopic detection of S. mansoni eggs in stool samples, a laborious, time consuming process relying on infrastructure (microscopes) and specific expertise. Low-intensity infections are frequently missed [Nigo MM, PhD thesis, Basel 2020]

Other direct parasitological tests for intestinal schistosomiasis are the Kato-Katz (KK) [33] technique, the miracidia hatching test (MHT) [34], the salinity gradient [35] and on the recently developed FLOTAC [36-41] and Helmintex assay [42-47]. The KK technique has the advantage of egg quantification in fresh stool samples. An amount of approximately $41.7 \mathrm{mg}$ or $50 \mathrm{mg}$ of feces is placed in a $1.5 \mathrm{~mm}$ $\times 6 \mathrm{~mm}$ template hole. The number of eggs is then counted and extrapolated to $1 \mathrm{~g}[48,49]$, yielding infection density (Table 2). This method is still recommended by the WHO for diagnosis at the community level. MHT can be 
done using the miracidia hatching device [50] or by sieving stool sample through a nylon tissue bag for concentrating the eggs. Then, hatching is carried out in a well-lit room at a temperature of $25 \pm 3^{\circ} \mathrm{C}$ followed by counting of the swimming miracidia [34]. The FLOTAC technique is more sensitive when compared to the KK technique, but it requires specific equipment, flotation solution, a suitable preservative medium that can affect the outcome of the test [41]. The principle of the Helmintex test is based on conjugates that are formed between the magnetic particles and the iron that is present in the eggshell pores of $S$. mansoni. Other factors such as electrostatic forces or the surface ornamentation of the eggs play also a role [51].

In urinary schistosome infections, direct microscopy of filtered urine is used. After gentle homogenization, $10 \mathrm{~mL}$ of urine is filtered through a membrane on which the number of eggs is counted in the microscope at $40 \times$ magnification [52]. These methods are still considered as reference methods [53], in spite of their limited capability to identify schistosome infection consistently in lowendemic areas. The development of better diagnostic tools for case management and disease control is therefore required [13].

Table 1: Expression of the intensity of schistosome infection [52]

\begin{tabular}{|l|l|l|l|l|}
\hline $\begin{array}{c}\text { Types of } \\
\text { Schistosomiasis }\end{array}$ & $\begin{array}{c}\text { Intensity } \\
\text { expression }\end{array}$ & Light & Moderate & High \\
\hline $\begin{array}{c}\text { Intestinal } \\
\text { schistosomiasis }\end{array}$ & $\begin{array}{c}\text { Eggs per gram } \\
\text { of stool }\end{array}$ & $1-99$ & $100-399$ & $\geq 400$ \\
\hline $\begin{array}{c}\text { Urogenital } \\
\text { schistosomiasis }\end{array}$ & $\begin{array}{c}\text { Eggs per } 10 \mathrm{~mL} \\
\text { of urine }\end{array}$ & $<50$ & $\geq 50$ \\
\hline
\end{tabular}

\section{Parasite-derived material detection}

Adequate differentiation between past and current infection requires assays, which detect circulating parasite antigens. The existence of such antigens was first described by [54-65], and an inventory has been published [66]. The most thoroughly investigated antigens are the circulating anodic antigen (CAA) [67], a gutassociated proteoglycan (GASP) [68] and the circulating cathodic antigen (CCA), originally named the M-antigen [69], which is a polysaccharide antigen emanating from the worm gut [70]. They are named relatively to their electrophoresis migration [71]. Their presence in patients corresponds well with active infections [56, 61]. Detection of circulating antigens could be used as well as for the evaluation of chemotherapy efficacy [6].

Other antigens as targets for diagnosis have been reported: schistosome adult worm antigen (SAWA), schistosome egg antigen (SEA), enzymes, parasite proteins, and tegument antigens; they can be detected in patient serum $[72,73]$. As some antigens are cleared by kidneys, urinalysis can produce evidence of their presence in schistosomiasis due to $S$. japonicum [74], S. haematobium [20] and $S$. mansoni [75]. Antigens from virtually all stages of the schistosome life cycle have been tested for immunodiagnostic potential and methods for their direct detection in blood, stool, or urine had been developed. Methods for detecting circulating antigens generally involve the capture of the antigen by a monoclonal or polyclonal antibody, with specificity for repeated epitopes on the antigen. In most cases, specific monoclonal antibodies are used [74]. Examples of these immunoassays are ELISA [31], radio-immuno-assay (RIA) [76, 77], and direct fluorescent antibody tests [78-80].

Lateral flow immuno-chromatographic assays or RDT are used for diagnosing antigens in serum [81], and in urine samples [82, 83]. They provide rapid results, are a non-invasive technique and are easy to use because they are typically cassettes or dipsticks [84, 85]. Details on technical procedures can be found in the cited literature [86]. Figure 2 shows an RDT for CCA in urine for the detection of S.mansoni. RDTs permit detection of active infections and 
are efficient in testing of large numbers of samples. However, they are frequently false negative due to inhibitory host antibodies [77] and often cannot distinguish between infections of different species because they are not species specific [14]. Diagnostic specificity of these tests is high because few false-positive are

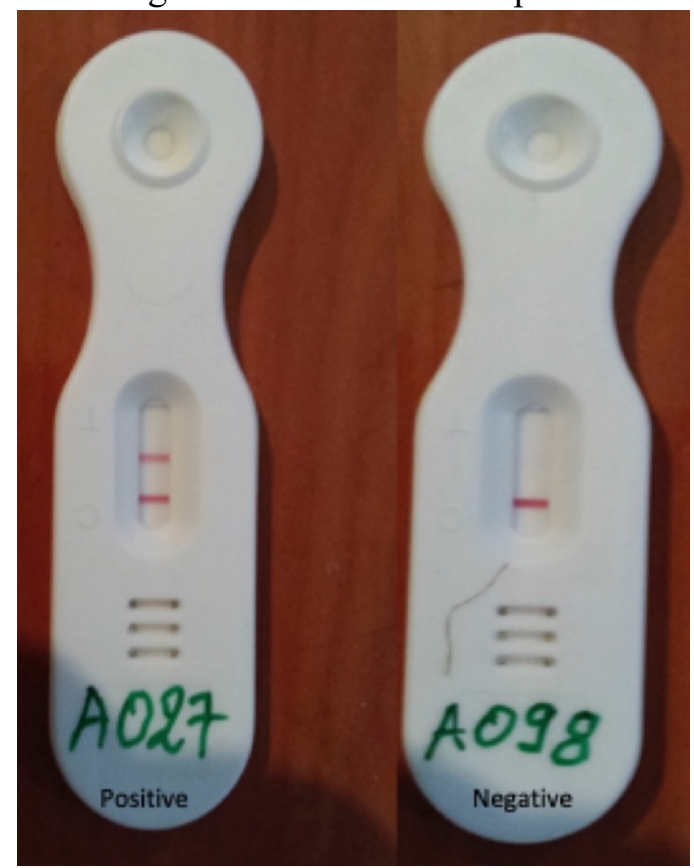

Figure 2: Rapid diagnostic test for circulating cathodic antigen allows point-of-care diagnosis of Schistosoma infection. Field studies [Nigo MM, PhD thesis, Basel 2020] have shown very good sensitivity when prevalence and parasite load is high, but sub-optimal sensitivity for low-grade infection.

\section{Antibody detection (AbD)}

Schistosoma infection activates specific immunoglobulin-dependent responses against several parasite antigens [90]. Most AbD assays measure serum immune reactivity to SAWA and SEA preparations for diagnostic purposes, using crude extracts, or parasite tegument proteins. AbD assays exhibit a modest sensitivity and a limited specificity although several antigens are available for diagnostic purposes, and some studies have shown their superiority to parasitological methods in lowendemic areas (LEAs) [91]. Nonetheless, AbD is more attractive for monitoring areas of controlled transmission and are important for the diagnosis of atypical forms like schistosome neuro-infection [22, 23]. Screening and diagnosis should rely on the use of 2 or more immunological tests to improve sensitivity because the test result depends on worm burden. found outside endemic areas and circulating antigen levels generally correlate with excreted egg counts [87-89]. AgD assays need to be evaluated further and are not currently considered as a suitable replacement for traditional diagnostic tests $[28,29]$.

$\mathrm{AbD}$ assays include various forms of RIA and ELISA, indirect immunofluorescence (IIF), complement fixation, indirect agglutination of erythrocytes or other tests, of which each has their specific weaknesses [92]. Many of these diagnostic techniques were miniaturized. Detection of antibodies in patient serum or cerebrospinal fluid (CSF) became possible [93]. Most AbD assays exhibit high sensitivity; however, they show limited specificity due to crude antigen preparations. They allow early diagnosis before oviposition of the worm [94, 95]. With the interpretation of the results, one has to take into account a possible persistence of host antibodies after the patient is cured [96, 97].

\section{Alternative methods}

Hematuria and proteinuria are associated with S. haematobium infection and are therefore often used for indirect diagnosis or as screening tool for schistosome infection [97, 98]. The cheap urine dipsticks for macroscopic hematuria and proteinuria detection are being used to guide treatment and public health interventions for S. haematobium. Hematuria is relatively specific for infection in a $S$. haematobium endemic area. However, hematuria has a variable sensitivity [99].

\section{Molecular approaches}

Although PD methods have proven to be inadequate as a gold standard, advances in the development of antigen and antibody detection assays are not sufficient to allow their use either universally or as a reliable single detection approach in schistosomiasis diagnosis, particularly in areas of low endemicity [24]. To overcome the shortcomings of both parasitological and immunological methods, the development of more sensitive and more specific molecular diagnostic tools diagnosis is desirable. The availability of DNA detection techniques may evolve to potentially valuable tools in the diagnosis of a schistosome infection. DNA-based assays have also proven to be useful for cure assessment [24]. The PCR 
technique has shown its clinical value in a wide variety of infectious diseases and in a variety of sample types including blood, urine, and saliva [100]. It has been successfully used for the sex determination of the cercariae in Schistosoma sp. studies and in the development and application of new techniques to generate expressed sequence tags. Hamburger et al. [101, 102] developed a PCR protocol that was based on the amplification of a highly repetitive DNA sequence for monitoring $S$. mansoni infestation in water-based on DNA sequences from S. mansoni cercariae. According to Reithinger et al. [103], PCR assays can be divided into 3 distinct formats: namely the midtech approach, represented by conventional PCR, the high-tech represented by real-time PCR and the low-tech, represented by LAMP. PCR-based methods are considered to be highly sensitive and a detection limit is $1 \mathrm{fg}$ of $S$. mansoni of genomic DNA has been reported [24]. PCR can be performed on feces, urine or serum $[27,73,104]$. In other studies, the use of PCR has been reported for diagnosing female genital $S$. haematobium infection and low intensity of $S$. japonicum infections in stool samples [105, 106], and for detection and quantification of $S$. mansoni and $S$. haematobium when present with other parasitic co-infections [107]. Superior accuracy, sensitivity, and specificity in areas with a low intensity of infection have been observed using antigen detection by PCR-based methods. It can be used to efficiently detect an active infection in almost $60 \%$ of $\mathrm{IgG}$ positive individuals who do not excrete eggs [104, 108]. Different studies demonstrated that the absence of amplification of other helminth DNA in a PCR assay is a strong indicator of its speciesspecificity [109]. Thus, PCR is more sensitive than the KK technique. However, Gomes and Enk $[104,110]$ found different results in samples tested by conventional PCR and microscopy. They observed that up to $41.6 \%$ of samples negative by KK are positive by PCR and that PCR assays for $S$. mansoni diagnosis increase prevalence estimates to above $38 \%$, whereas positivity on K-K assay ranges from 18 to $30.9 \%$. A high degree of specificity may render it preferable to serological techniques. Even though these studies have demonstrated that PCR-based technologies are reliable, specific and sensitive tools, they are not widely used in low-income countries because highly skilled personnel and expensive cyclers are needed. The use of thermocycler machines to amplify DNA is severely hampered in field situations where electric power is unstable, intermittent or absent. There is a real need to render these techniques easier to use and technically more robust, such that obvious advantages of these tests can be translated into broad clinical utility even in resourceconstrained locations [111, 112].

The value of standardized quantitative PCRbased methods for the detection of Schistosoma infection was shown in experimental settings [94]. RT-PCR was found highly sensitive and specific in the detection of active schistosomiasis [109]. Wichmann [113] found that blood-based RT-PCR detected $95 \%$ of true positive patients when, in contrast, antischistosome antibodies and microscopy were positive only in $72 \%$ and $25 \%$ of cases respectively. Moreover, RT-PCR also permits the determination of infection intensity in samples with a low parasite burden. Obeng [114] examined urine specimens from children to detect CCA, and then performed RT-PCR on urine sample after storage at $-80^{\circ} \mathrm{C}$ using internal-transcribed-spacer-2 (ITS2) sequences for $S$. haematobium. When compared with eggs in the urine, the RT-PCR test was $100 \%$ sensitive, yet specificity was low. The detectable product was dependent on the number of eggs passed in the specimen and the authors postulated that the template DNA was derived from the eggs.

Currently, all PCR variants demand more sophisticated laboratory equipment and a greater operational effort when compared with the KK technique, in terms of low costs and ease of operation [27].

New DNA detection using new technologies, such as LAMP (Figure 3), have been developed. LAMP amplifies a few copies of DNA to $10^{9}$ copies in less than an hour with high specificity and efficiency under isothermal conditions. LAMP method employs a Bacillus stearothermophilus (Bst) DNA polymerase and a set of 4 [115] to 6 or more specially designed primers: inner forward primer (FIP), inner backward primer (BIP), outer forward primer (F3), outer backward primer (B3), loop forward (LF) and loop backward that recognize a total of 6 distinct sequences on target DNA. A 
standard LAMP reaction consists of a large number of reaction components, namely the enzyme and its buffer, 3 sets of primers of varying concentrations, and a detection dye. Significant progress has been made with the modification of the LAMP method. The LAMP reaction produces large amounts of magnesium pyrophosphate $\left(\mathrm{Mg}_{2} \mathrm{P}_{2} \mathrm{O}_{7}\right)$ and double-stranded (dsDNA) avoiding post DNA amplification manipulation. LAMP has shown high sensitivity, detecting $0.08 \mathrm{fg}$ of genomic DNA [116].
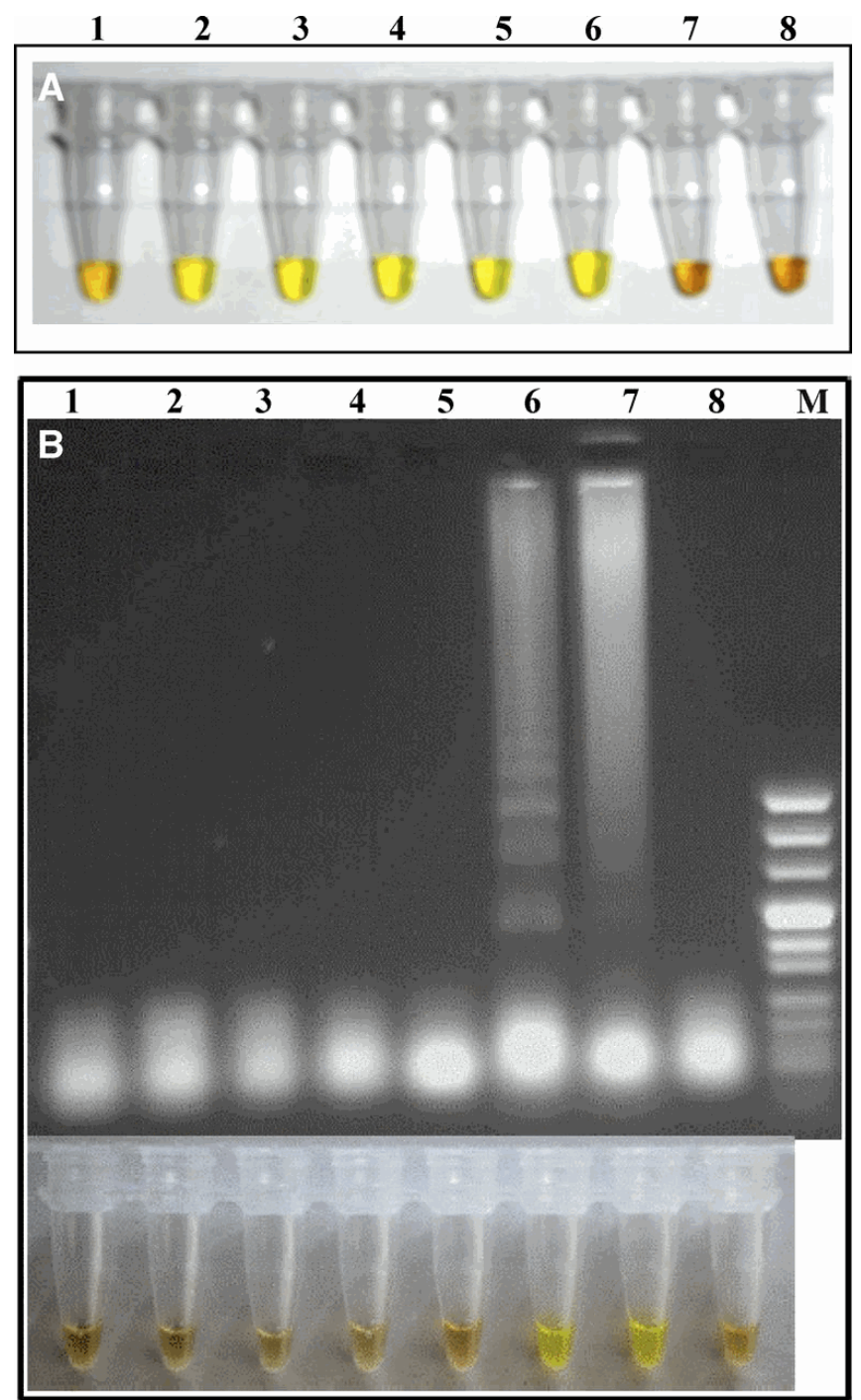

Figure 3: Isothermal loop-mediated amplification (LAMP) for the detection of Schistosoma DNA. Yellow colour indicates detection of specific DNA. A1-6: Schistosoma positive snails; A7-8: negative controls. B: evaluation of LAMP result with agarose electrophoresis: B1-5,8: negative control. B6-7: Schistosoma positive snails. The reduced hardware requirements for LAMP compared to conventional PCR and the simple, colorimetric readout may lead to field-applicable high-sensitivity molecular testing. From Hamburger et al [118].

The LAMP method has the advantage of being able to amplify target DNA from partially processed and/or non-processed samples [117]. It can be conducted in less advanced field laboratories with much less intensive training of local laboratory personnel. When a large number of examinations are undertaken, the use of LAMP method could save time and financial resources [118]. This method has demonstrated superior accuracy when compared to the conventional PCR in detecting several pathogens such as viruses, bacteria, protozoa in 
humans [119]. In the diagnosis of schistosomiasis, LAMP was found highly sensitive for the detection of $S$. japonicum infection pre- and post-chemotherapy in experimental settings [120]. LAMP was recently used for the detection of $S$. japonicum in human serum samples. It revealed high analytical sensitivity (96.7\%) detecting $0.08 \mathrm{fg}$ of parasite DNA and a specificity of $100 \%$ [121]. Fernandez-Soto [1] are leading in development of a sensitive, specific, costeffective and easy to perform LAMP assay for early diagnosis of $S$. mansoni in feces. However, the amplification mechanism of LAMP may easily lead to carryover and therefore false-positive results.

\section{Emerging diagnostic technologies for}

\section{schistosomiasis}

Advances in micro-and nanofabrication technologies have greatly contributed to improving POC laboratory diagnosis [122]. Benefits of miniaturization include low consumption of costly reagents and power, minimized handling of hazardous materials, short reaction times, portability and versatility in design, and capability for parallel operation, all of which are particularly important for POC diagnosis in the tropical and developing countries where schistosomiasis is endemic [123]. Important developments in this field are presented below in Table 2 .

Table 2: Comparison of the main characteristics of diagnostic tests for schistosome infection

\begin{tabular}{|c|c|c|c|c|c|c|}
\hline \multicolumn{7}{|c|}{ Characteristics } \\
\hline Test & Methods & Advantages & Disadvantages & $\begin{array}{l}\text { Price } \\
\text { (US\$) }\end{array}$ & $\begin{array}{l}\text { On } \\
\text { market }\end{array}$ & Reference \\
\hline Microscopy & $\begin{array}{c}\text { Egg } \\
\text { detection }\end{array}$ & $\begin{array}{l}\text { Simple } \\
\text { Quantification }\end{array}$ & $\begin{array}{l}\text { Limited } \\
\text { sensitivity } \\
\text { Laborious } \\
\end{array}$ & 0.4 & Yes & [77] \\
\hline $\begin{array}{c}\text { ELISA; } \\
\text { DDIA; IHA }\end{array}$ & $\begin{array}{l}\text { Antibody } \\
\text { Detection }\end{array}$ & Sensitive & $\begin{array}{c}\text { Limited } \\
\text { specificity }\end{array}$ & ${ }^{5} 5.0^{*}$ & Yes & [52] [124] \\
\hline RDTs & $\begin{array}{r}\text { Antigen } \\
\text { Detection }\end{array}$ & $\begin{array}{l}\text { Rapid; Large } \\
\text { scale testing; } \\
\text { Specific }\end{array}$ & $\begin{array}{l}\text { Variable } \\
\text { sensitivity; False } \\
\text { positives }\end{array}$ & 2.6 & $\begin{array}{l}\text { Not } \\
\text { yet }\end{array}$ & [77] [78] \\
\hline $\begin{array}{l}\text { ELISA } \\
\text { DDIA } * * *^{*} \\
\text { IHA }^{* * * *}\end{array}$ & $\begin{array}{l}\text { Antigen } \\
\text { Detection }\end{array}$ & $\begin{array}{l}\text { Sensitive } \\
\text { Specific }\end{array}$ & $\begin{array}{l}\text { Variability in } \\
\text { test results }\end{array}$ & & Yes & $\begin{array}{c}{[126]} \\
{[127][128]}\end{array}$ \\
\hline PCR & $\begin{array}{c}\text { DNA } \\
\text { detection }\end{array}$ & $\begin{array}{l}\text { Highly } \\
\text { sensitive } \\
\text { Specific }\end{array}$ & $\begin{array}{l}\text { Laborious; } \\
\text { Expensive; } \\
\text { Instrumentation; } \\
\text { Not quantitative }\end{array}$ & 6.4 & Yes & {$[17][106]$} \\
\hline RT-PCR & $\begin{array}{l}\text { RNA } \\
\text { detection }\end{array}$ & $\begin{array}{l}\text { Highly } \\
\text { sensitive } \\
\text { Quantitative }\end{array}$ & $\begin{array}{l}\text { Laborious; } \\
\text { Expensive; } \\
\text { Instrumentation; }\end{array}$ & 7.7 & $\begin{array}{l}\text { Not } \\
\text { yet }\end{array}$ & $\begin{array}{l}{[114]} \\
{[128]}\end{array}$ \\
\hline LAMP & $\begin{array}{c}\text { DNA } \\
\text { detection }\end{array}$ & $\begin{array}{r}\text { Highly } \\
\text { sensitive } \\
\text { Accurate }\end{array}$ & $\begin{array}{l}\text { Some } \\
\text { Instrumentation, } \\
\text { false positive }\end{array}$ & & $\begin{array}{l}\text { Not } \\
\text { yet }\end{array}$ & $\begin{array}{c}{[1][75]} \\
{[120][129]}\end{array}$ \\
\hline
\end{tabular}

* Price without including equipment use and personnel labor [24]

** Estimated price

DDIA = disperse dye immunoassay; DNA = deoxyribonucleic acid; ELISA = enzyme-linked immunosorbent assay; IHA = indirect hemagglutination test; LAMP = loop mediated isothermal amplification; RNA = ribonucleic acid. 
Song et al. [129] presented an instrument-free disposable microfluidic POC device for the on-site detection of schistosome parasite infection in blood samples obtained from a finger prick. On board a reaction chamber is present and once filled with water, it is heated to its operating temperature, which is used to incubate a LAMP reaction. The emission of fluorescent light is detected by eye or with the camera of a smartphone.

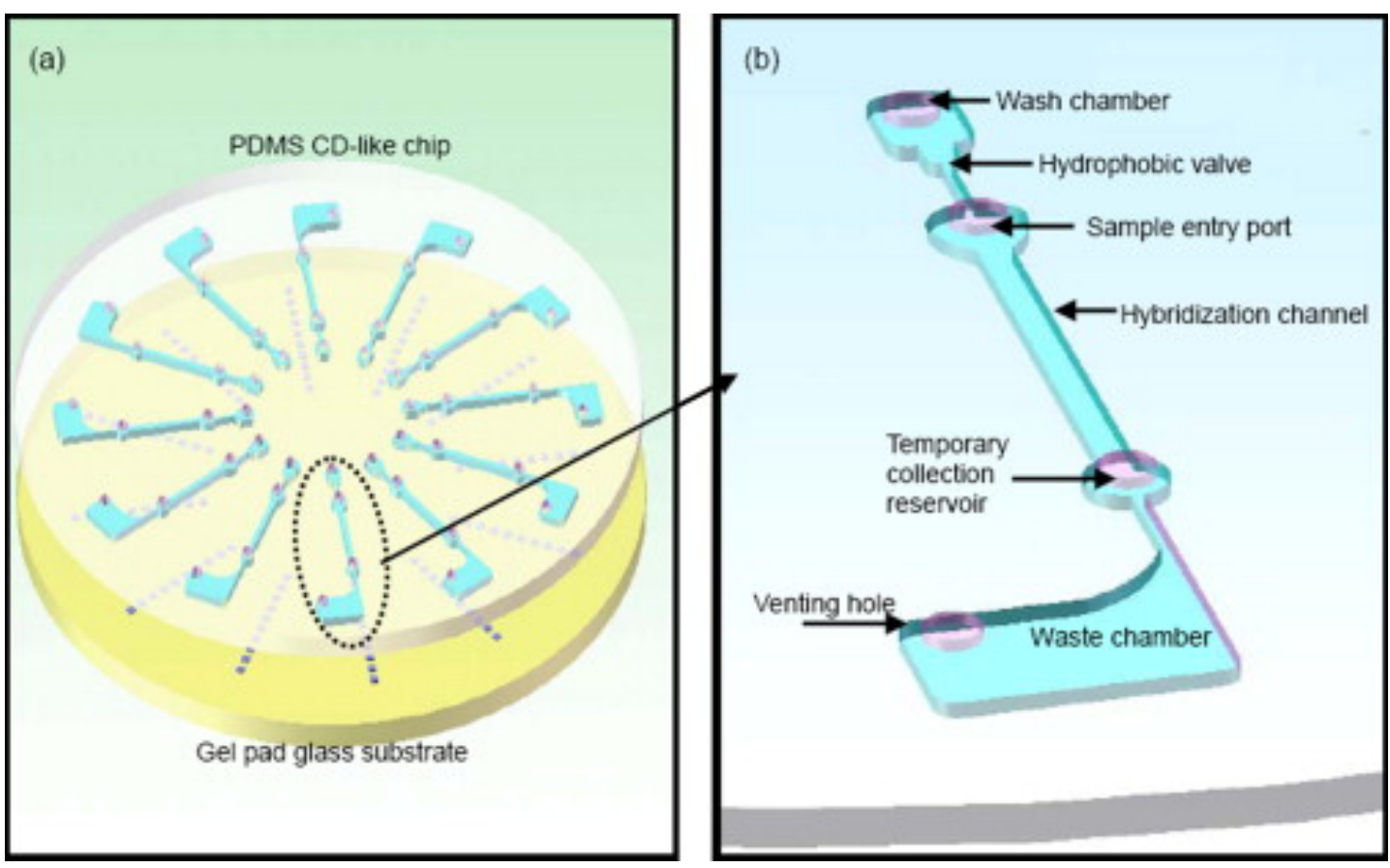

Figure 4: A compact disc (CD)-like microfluidic rotating disc for DNA hybridization assays in nanoliter samples proposed by Li et al [128, reprinted with permission]. Fluid handling is driven by differential rotation of the disk, allowing flow control without the need to interact with the disk. Parallel processing can be performed on multiple channels.

This device has potential, however, the discussed crossover contamination when using LAMP needs to be taken into account and thus a second test confirming an infection might be necessary.
A microfiltration device for the diagnosis of urogenital schistosomiasis was developed by Xiao Y et al. [130], shown in Figure 5
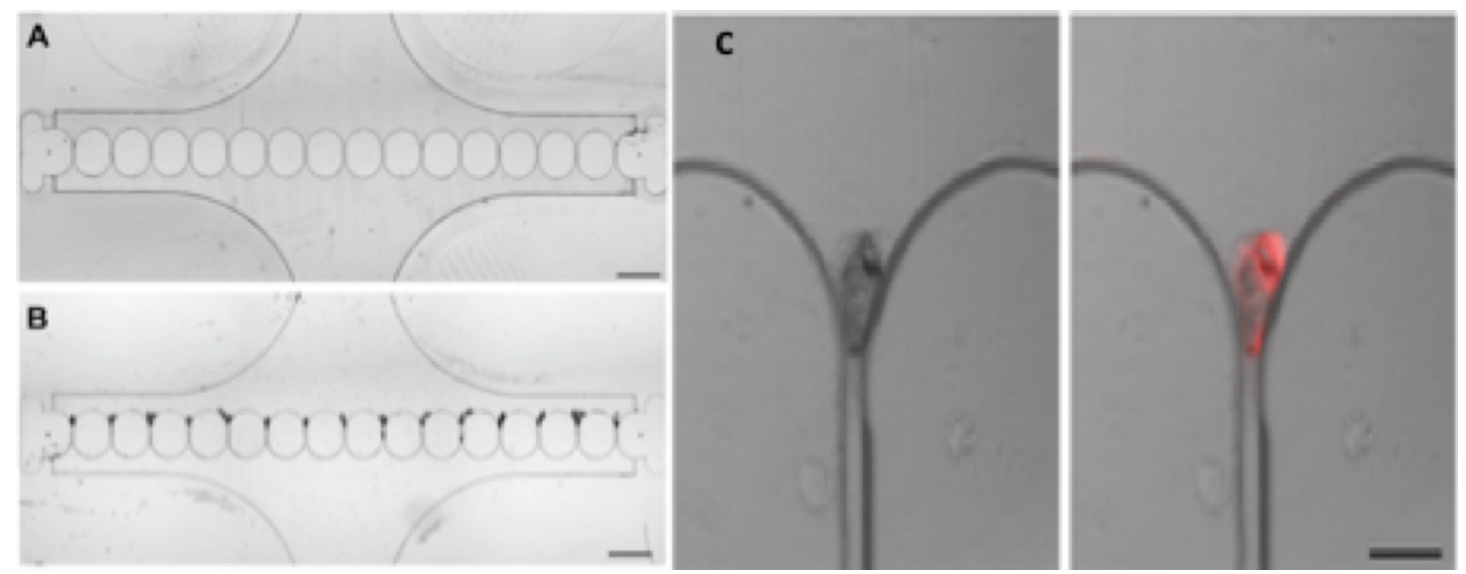

Figure 5: Microfluidic device for trapping and fluorescence-based identification of Schistosoma hematobium eggs from urine. A: microfluidic trap. B: trapped Schistosoma eggs in brightfield imagine. C: with fluorescence microscopy overlay. Adapted from Xiao Y et al [130, reprinted with permission]. 
In this device $S$. haematobium eggs are trapped and analysed by using brightfield microscopy. For POC use, it might be possible to design this device such that a smartphone camera can be used.

Capillary test strips or LF assays can also be considered as fairly simple microfluidic systems and are the most successful POC tests to date. LF devices can be reduced to their bare ingredients - patterned filter paper impregnated with reagents resulting in microfluidic paperbased analytical devices ( $\mu$ PADs). Paper-based techniques allow performing multiple, simultaneous, and independent assays with multiplexed detection. Fast prototyping and production techniques for paper-based diagnostic devices have been proposed [123]. $\mu \mathrm{PADs}$ are inexpensive, easy to use, lightweight to transport, compatible with biological samples and may be handled in remote settings by non-trained personnel.

Ishii [131] developed microfluidic quantitative PCR (qPCR) on environmental samples in a quadruplicate with a dynamic array under specific detection conditions. They found that the quantitative performance of microfluidic qPCR was similar to the conventional qPCR. However, it specifically detected pathogens in stool, demonstrating that this method may be applied to the rapid identification of disease causing-agents for diagnostic purposes. They also quantified multiple targets simultaneously in water samples. Therefore, they concluded that the microfluidic qPCR systems can be applied to the quantification of multiple pathogens in environmental samples. Despite the efforts made in developing microfluidic POC diagnostic devices, microfluidic systems for detection of schistosome infection are developed but still in its infancy due to issues as device sensitivity, multiplex analysis capabilities, assay stability/shelf life, and fabrication cost remain. Standardized evaluation of the performance microfluidic versus other POC technologies in a real-world setting is needed.

\section{Microarrays}

Microarrays are usually a glass slide but may also be a microtitre plate or on board of a microfluidic device. Small areas or micro-wells are coated with different probes or biological material for the simultaneous detection of multiple targets. In this way, thousands of biomolecular interactions can be probed in parallel [132]. Microarrays can offer multicomponent information, dynamic compensation for sample matrix effects, detection of malfunction/deterioration, and improved selectivity through signal pattern analysis. Recent progress has brought microarrays to the forefront of clinical diagnostics and medical research. DNA microarrays appear suited for highly parallel detection and identification of microorganisms from clinical samples [133] and therefore promise more rapid, accurate, and costeffective detection of pathogens compared to culture techniques or conventional immunoassays.

Genomes of all 3 major schistosome species have been sequenced [134], and several postgenomic approaches and high throughput methods have been developed to take advantage of this wealth of information [135]. One such approach is a schistosome-specific microarrayed protein, containing 232 unique antigens [136]. Many of these arrayed proteins are novel molecules and the majority is from $S$. japonicum, with the remainder from $S$. mansoni. They can be then probed with antibodies from immune hosts as a powerful new technology for vaccine antigen discovery [137]. Using this approach, McWilliam [138] identified several novel antigens, which may be important targets for vaccine development.

Nanotechnology enabled diagnostics

Nanotechnology is based on structures and materials in the nanometre size range. Such nano-sized structures and materials differ from microscale structures and materials in various aspects, for example in the very high surface per weight, the occurrence of specific physical effects like particle surface plasmon effects not readily observed in the micro- or macro scale. Gold nanoparticles are stable, can bind biomolecules, and are already used widely in many different kinds of applications such as imaging and biomedical diagnosis [139]. An example is the amperometric immunosensor for the detection of S. japonicum antigen [140]. This sensor is made of carbon paste coated with a layer of chitosan on which a monolayer of 
gold nanoparticles was formed. Antibodies against $S$. japonicum antigen were linked to the gold monolayer and used to detect this antigen with a detection limit of $0.06 \mu \mathrm{g} / \mathrm{mL}$ [141]. More recent work is the highly sensitive detection of $S$. mansoni DNA [142], where aminated magnetic particles and gold nanoparticles are immobilized on monolayers of mercaptobenzoic acid. Thiolated DNA probes are immobilized on the surface of the nanoparticles. Evaluation of the surface was performed by using an atomic force microscope and the electrochemical processes (binding of the antigens) were measured by using electrochemical impedance spectroscopy and cyclic voltammetry. S. mansoni DNA from cerebrospinal fluid and serum could be detected with a detection limit of 0.685 and $0.781 \mathrm{pg} / \mu \mathrm{L}$ respectively. Such sensors will require further development to render their application suitably simple and robust for application in the field [143].

\section{Diagnostic tests in the "real world" of} field practice

\section{Parasitological methods}

In most locations worldwide and in particular, in endemic areas, laboratory diagnosis of schistosomiasis is still based on parasite egg detection in feces or urine. Direct or indirect microscopy remains in use in POC although being laborious, and of limited sensitivity because of the daily egg count fluctuation. However, negative microscopy does not disprove the possibility of infection in people living in or coming from endemic areas. Results need to be validated by improved diagnostic techniques. Urine microscopy after centrifugation or filtration is required for urogenital schistosomiasis [144]. It presents a good specificity but a low sensitivity consecutive to variable egg release. Nevertheless, in endemic settings, efficiency could reach when urine is collected between 10 am and $2 \mathrm{pm}$ according to the egg excretion pattern [73]. However, during field surveys, urine microscopy presents some difficulties.

\section{Immunoassays}

Immune host response against schistosome antigens has been an alternative way for diagnosis. For many years several immunodiagnostic techniques have been developed. AbD immunoassays are widely used. However, since CCA and CAA can be detected by substituting other antigens, both processes can indiscriminately be used. Immunoassays based on CAA, SAWA or SEA circulating antibodies detection are already in use. Their validity is usually variable. Immunoassays complete direct microscopy by detection of specific antibodies in serum and cerebrospinal fluid. AbD is the best tool for field diagnostic activities. However, they usually exhibit a weak specificity. Frequently, reaction with other parasites antigens compromises the specificity. Nevertheless, antigens used in immunoassays have proven crucial test sensitivity and specificity element [145].

\section{Molecular methods}

Molecular methods present high performance in use [104, 111]. PCR is highly accurate, highly sensitive and specific for the detection of $S$. mansoni. They also permitted $S$. mansoni increased prevalence estimates, whereas KK assay underestimated them. However, [107] reported discordant results in samples tested by conventional PCR and KK techniques, and negative PCR results in KK-positive samples.

RT-PCR was found highly specific and sensitive in $S$. japonicum and $S$. haematobium detection [114]. Compared to microscopy and immunoassays, RT-PCR can be the best marker after chemotherapy [104]. Although owning these qualities, PCR and RT-PCR are cumbersome and costly methods. Nucleic acid extraction stages improvement could perhaps lead to cost reduction [104]. DNA detection development by LAMP technologies promises to be the best alternative $[116,120]$.

\section{Emerging technologies}

The persistent transmission and widespread distribution of schistosome infection call for the development of new "gold standard" diagnostic assays. Identification and detection of infected hosts as well as new diagnostic tests for field applications [118] are essential for case management and disease control. These tests must be more sensitive, more specific, and affordable for point-of-care diagnostic strategies (see also Table 3.3). There are 2 important challenges: (1) although parasitological tests remain central for schistosomiasis diagnosis, they have proven their accuracy inability, (2) immunoassays and usual molecular techniques have demonstrated 
their weaknesses. To overcome these shortcomings, resorting to statistical indirect methods to assess the accuracy is frequently required. For example, the use of latent class analysis (LCA) [21, 84, 146] has proven its capability for validation of the sensitivity and specificity of the tests [21].
With the goal of the development of an automated and/or integrated device, microfluidic platforms procure hope. Miniaturization could enable affordable POC diagnostic tests for end-users in low resource settings $[147,148]$

Table 3: Criteria/wish list for future diagnostic tests [116, 148, 149]

ASSURED criteria:

Affordable by those at risk of infection (less expensive for patients and for health services);

Sensitive (few false negatives): able to diagnose light infections ( 1 egg per gram for intestinal and 1 egg/10 $\mathrm{mL}$ for urinary schistosomiasis);

Specific (few false-positives);

User-friendly (simple to perform in a few steps with minimal training);

Robust (Field-adapted: stable in ambient temperature conditions - from 4 to $30^{\circ} \mathrm{C}$ ) - does not require refrigerated storage) and rapid (results available in 30 minutes);

Equipment free (less instrumentation, no computer use);

Deliverable to the end users

Inexpensive to produce (cost target of less than 1 US\$ per test to ensure commercial viability)

Producing a visual readout (results can be read by naked eyes)

Using non-invasive samples (urine, stool, saliva, sputum)

\section{New challenges and uncertainties for more adapted tests in different settings}

Clinical scenarios for schistosomiasis test vary widely: For disease control in communities with a very high prevalence, a test with imperfect sensitivity will predictably be associated with a significant number of false negatives, rendering treatment of everybody the most rational approach and implying that individual testing only adds cost without adding benefit and is therefore not required. In contrast, in a low-prevalence situation near the eradication threshold, where infection severity typically is also low, a test with low sensitivity may miss many of those with persistent, but low parasite load, so that the infection cycle is not interrupted and completing eradication becomes infeasible. In this situation, a test with near perfect sensitivity like LAMP would be needed to identify affected individuals, but because most individuals undergoing the test will be negative, such testing may become unaffordable for developing countries. The situation is yet different in travellers from affluent countries, where optimal sensitivity is desired, and event relatively costly tests are economically feasible.

Despite the impressive advances on the technology front, an integrated approach with practical, adapted, affordable rapid diagnostic tools in combination with suited clinical and epidemiologic testing strategies is still to be defined. Recent clinical observations of lower than expected current cure rates with the mainstay of therapy, praziquantel, particularly when sensitive testing is used for treatment success monitoring, also raise the concern of slow, but progressive drug resistance development. This would add to the challenge for novel tests that not only detect a parasite but also determine its sensitivity to standard drug treatment.

Reliable access to electricity for diagnostic devices, even simple microscopes, is a pervasive problem in developing countries. Fortunately, recent progress in miniaturization, battery technology, low power embedded high performance computing[149] and solar cell technology has led to development of portable, battery driven diagnostic devices for parasitic disease, e.g. portable microscopy [150] and portable molecular diagnostics like LAMP [151] that are suited for use in very low 
resource environments. Thus, alternative

developing countries and basic healthcare energies have the capability to benefit

profoundly.

Table 4: Needs of schistosomiasis tests according to different settings

\begin{tabular}{|l|l|}
\hline $\begin{array}{l}\text { Schistosoma infection diagnostic } \\
\text { methods }\end{array}$ & Needs \\
\hline Parasitological & Improved microscopy \\
\hline Immunoassays & RDTs; Dipsticks \\
\hline Molecular & Miniaturized LAMP \\
\hline Emerging & Microfluidic point-of-care devices (mobile phone based) \\
\hline
\end{tabular}

LAMP = loop mediated isothermal amplification; RDT = rapid diagnostic test.

\section{Conclusion}

Current parasitological methods have well-documented weaknesses. They are often too resourceconsuming, laborious or expensive for broad use in endemic areas. In addition, they often do not allow distinction between latent versus recent infection. Immunoassays that have long been perceived as replacement or second option because of their high sensitivity, often fail due to their low specificity. However, combination of several test modality may improve reliability of testing, but this involves increased cost and time consumption. Use of molecular techniques offers a real alternative because they offset the weaknesses of the other methods while enhancing their strengths. Nevertheless, they remain laborious and expensive. The LAMP approach to nucleic acid detection appears to be a valuable platform but needs further development in terms of miniaturization, reduction of carryover contamination risk and develop instrumentation that is field-ready. New microfluidic devices have a significant potential for improving diagnosis based on protein and nucleic acid detection. The integration of multiple test modalities into a robust point-of-care device that is easy to handle and fulfills the ASSURED criteria appears technically feasible and when applied to the diagnosis of Schistosoma may revolutionize clinical diagnosis and greatly enhance public health efforts in this important disease.

Thus, there remains a significant unmet need for new tests that are highly sensitive, highly specific, adapted to field conditions and allow point-of-care diagnosis, are inexpensive and are suited to contribute either to mass treatment in high prevalence areas, eradication in low-prevalence areas, or individual diagnosis in symptomatic individuals outside such scenarios. The rapid evolution observed in nanotechnologies and microfluidics, as well as in molecular diagnostics, will hopefully render technologic progress also beneficial for the poorest in regions where testing may contribute most to humankind.

\section{Acknowledgment:}

We gratefully acknowledge funding and support by an anonymous donor, with additional contributions by CLINAM Foundation, the EU FP7 project "Discognosis" and Andreas Löffler, M.D.

\section{Conflict of Interests}

The authors declare no conflicts of interest. For signed statements, please contact the journal office: editor@precisionnanomedicine.com

Quote this article as: Nigo MM, Saleeb-Beugelaar G, Battegay M, Odermatt P, Hunziker P, Schistosomiasis: from established diagnostic assays to emerging micro/nanotechnology-based rapid field testing for clinical management and epidemiology, Precis. Nanomed. 2020;3(1):439-458, https://doi.org/10.33218/prnano3(1).191205.1

\section{References}

1. Fernandez-Soto, P., et al., A Loop-Mediated Isothermal Amplification (LAMP) Assay for Early Detection of Schistosoma mansoni in Stool Samples: A Diagnostic Approach in a Murine Model. Plos Neglected Tropical Diseases, 2014. 8(9).

2. Tidy, C. Schistosomiasis. 2013; Available at: www.patient.co.uk/doctor/schistosomiasis-pro. 
3. Gao, F.H., et al., Fine scale Spatial-temporal cluster analysis for the infection risk of Schistosomiasis japonica using space-time scan statistics. Parasites \& Vectors, 2014. 7.

4. Kloos, H., et al., Combined methods for the study of water contact behavior in a rural schistosomiasis-endemic area in Brazil. Acta Tropica, 2006. 97(1): p. 31-41.

5. Taman, A. and S.N. El-Beshbishi, Laboratory diagnosis of schistosomiasis mansoni: Current status and future trends. Asian Pacific Journal of Tropical Medicine, 2019. 12(6): p. 243-249.

6. $\mathrm{Lu}, \mathrm{Y}$., et al., Identification and profiling of circulating antigens by screening with the sera from schistosomiasis japonica patients. Parasites \& Vectors, 2012. 5.

7. WHO, Status of schistosomiasis endemic coutries: 2017. 2019.

8. Gaze, S., et al., An Immunomics Approach to Schistosome Antigen Discovery: Antibody Signatures of Naturally Resistant and Chronically Infected Individuals from Endemic Areas. Plos Pathogens, 2014. 10(3).

9. Olveda, D.U., et al., Bilharzia in the Philippines: past, present, and future. International Journal of Infectious Diseases, 2014. 18: p. 52-56.

10. WHO, WHA 65.21 Elimination of schistosomiasis. 2012.

11. Patz, J.A., et al., Effects of environmental change on emerging parasitic diseases. International Journal for Parasitology, 2000. 30(12-13): p. 1395-1405.

12. WHO, Schistosomiasis. Key facts. 2019.

13. WHO. Strategic and business plan for the african network for drugs and diagnostics innovation (ANDI). 2019; Available from: https://www.who.int/tdr/publications/documents/sbp_andi.pdf?ua=1.

14. Kinkel, H.F., et al., Evaluation of Eight Serological Tests for Diagnosis of Imported Schistosomiasis. Clinical and Vaccine Immunology, 2012. 19(6): p. 948-953.

15. Adriko, M., et al., Data on the pre-MDA and post MDA interventions for Schistosoma mansoni and Schistosoma haematobium in a co-endemic focus in Uganda: 1951-2011. Data in Brief, 2018. 20: p. 991-998.

16. Ross, A.G.P., et al., A new global strategy for the elimination of schistosomiasis. International Journal of Infectious Diseases, 2017. 54: p. 130-137.

17. Ross, A.G.P. and Y.S. Li, Mass Drug Administration (MDA) for Schistosomiasis Reply. Journal of Infectious Diseases, 2015. 211(5): p. 849-+.

18. Ross, A.G.P., et al., Can Mass Drug Administration Lead to the Sustainable Control of Schistosomiasis? Journal of Infectious Diseases, 2015. 211(2): p. 283-289.

19. Ross, A.G.P., R.M. Olveda, and Y.S. Li, An audacious goal: the elimination of schistosomiasis in our lifetime through mass drug administration. Lancet, 2015. 385(9983): p. 2220-2221.

20. Ibironke, O.A., et al., Diagnosis of Schistosoma haematobium by Detection of Specific DNA Fragments from Filtered Urine Samples. American Journal of Tropical Medicine and Hygiene, 2011. 84(6): p. 998-1001.

21. Ibironke, O., et al., Validation of a New Test for Schistosoma haematobium Based on Detection of Dra1 DNA Fragments in Urine: Evaluation through Latent Class Analysis. Plos Neglected Tropical Diseases, 2012. 6(1).

22. Ferrari, T.C.A., A laboratory test for the diagnosis of neuroschistosomiasis. Neurological Research, 2010. 32(3): p. 252-262.

23. Ferrari, T.C.A. and P.R.R. Moreira, Neuroschistosomiasis: clinical symptoms and pathogenesis. Lancet Neurology, 2011. 10(9): p. 853-864.

24. Cavalcanti, M.G., et al., Schistosomiasis in areas of low endemicity: a new era in diagnosis. Trends in Parasitology, 2013. 29(2): p. 75-82.

25. Enk, M.J., et al., The effect of the number of stool samples on the observed prevalence and the infection intensity with Schistosoma mansoni among a population in an area of low transmission. Acta Tropica, 2008. 108(2-3): p. 222-228.

26. Carvalho, G.B.F., et al., Identification of Schistosoma mansoni candidate antigens for diagnosis of schistosomiasis. Memorias Do Instituto Oswaldo Cruz, 2011. 106(7): p. 837-843.

27. Pontes, L.A., E. Dias-Neto, and A. Rabello, Detection by polymerase chain reaction of Schistosoma mansoni DNA in human serum and feces. American Journal of Tropical Medicine and Hygiene, 2002. 66(2): p. 157-162. 
28. Coulibaly, J.T., et al., Accuracy of Urine Circulating Cathodic Antigen (CCA) Test for Schistosoma mansoni Diagnosis in Different Settings of Cote d'Ivoire. Plos Neglected Tropical Diseases, 2011. 5(11).

29. Coulibaly, J.T., et al., Accuracy of Urine Circulating Cathodic Antigen Test for the Diagnosis of Schistosoma mansoni in Preschool-Aged Children before and after Treatment. Plos Neglected Tropical Diseases, 2013. 7(3).

30. Utzinger, J., et al., New diagnostic tools in schistosomiasis. Clin Microbiol Infect, 2015. 21(6): p. $529-42$.

31. Doenhoff, M.J., P.L. Chiodini, and J.V. Hamilton, Specific and sensitive diagnosis of schistosome infection: can it be done with antibodies? Trends in Parasitology, 2004. 20(1): p. 35-39.

32. Colley, D.G. and W.E. Secor, Immunology of human schistosomiasis. Parasite Immunology, 2014. 36(8): p. 347-357.

33. Katz, N., A. Chaves, and J. Pellegrino, A simple device for quantitative stool thick-smear technique in Schistosomiasis mansoni. Rev Inst Med Trop Sao Paulo, 1972. 14(6): p. 397-400.

34. Zhu, H.Q., et al., Comparison of the Miracidium Hatching Test and Modified Kato-Katz Method for Detecting Schistosoma Japonicum in Low Prevalence Areas of China. Southeast Asian Journal of Tropical Medicine and Public Health, 2014. 45(1): p. 20-25.

35. Coelho, P.M.Z., et al., Use of a saline gradient for the diagnosis of schistosomiasis. Memorias Do Instituto Oswaldo Cruz, 2009. 104(5): p. 720-723.

36. Utzinger, J., et al., FLOTAC: a new sensitive technique for the diagnosis of hookworm infections in humans. Transactions of the Royal Society of Tropical Medicine and Hygiene, 2008. 102(1): p. 84-90.

37. Schnyder, M., et al., Comparison of faecal techniques including FLOTAC for copromicroscopic detection of first stage larvae of Angiostrongylus vasorum. Parasitology Research, 2011. 109(1): p. 63-69.

38. Knopp, S., et al., A single FLOTAC is more sensitive than triplicate Kato-Katz for the diagnosis of low-intensity soil-transmitted helminth infections. Transactions of the Royal Society of Tropical Medicine and Hygiene, 2009. 103(4): p. 347-354.

39. Knopp, S., et al., Diagnostic Accuracy of Kato-Katz and FLOTAC for Assessing Anthelmintic Drug Efficacy. Plos Neglected Tropical Diseases, 2011. 5(4).

40. Cringoli, G., et al., Fill-it, float-it: FLOTAC and Mini-FLOTAC for helminth diagnosis. Tropical Medicine \& International Health, 2013. 18: p. 10-10.

41. Cringoli, G., et al., FLOTAC: new multivalent techniques for qualitative and quantitative copromicroscopic diagnosis of parasites in animals and humans. Nat. Protocols, 2010. 5(3): p. 503-515.

42. Pinheiro, M.C.C., et al., The combination of three faecal parasitological methods to improve the diagnosis of schistosomiasis mansoni in a low endemic setting in the state of Ceara, Brazil. Memorias Do Instituto Oswaldo Cruz, 2012. 107(7): p. 873-876.

43. de Souza, R.P., et al., Criteria for identification of Schistosoma mansoni eggs in faecal sediments prepared with the Helmintex method and stained by ninhydrin. Memorias Do Instituto Oswaldo Cruz, 2019. 114.

44. Favero, V., et al., Optimization of the Helmintex method for schistosomiasis diagnosis. Experimental Parasitology, 2017. 177: p. 28-34.

45. Lindholz, C.G., et al., Study of diagnostic accuracy of Helmintex, Kato-Katz, and POC-CCA methods for diagnosing intestinal schistosomiasis in Candeal, a low intensity transmission area in northeastern Brazil. Plos Neglected Tropical Diseases, 2018. 12(3).

46. Oliveira, W.J., et al., Evaluation of diagnostic methods for the detection of intestinal schistosomiasis in endemic areas with low parasite loads: Saline gradient, Helmintex, Kato-Katz and rapid urine test. Plos Neglected Tropical Diseases, 2018. 12(2).

47. Caldeira, K., et al., Comparison of the Kato-Katz and Helmintex methods for the diagnosis of schistosomiasis in a low-intensity transmission focus in Bandeirantes, Parana, southern Brazil. Memorias Do Instituto Oswaldo Cruz, 2012. 107(5): p. 690-692.

48. Qian, M.B., et al., Accuracy of the Kato-Katz method and formalin-ether concentration technique for the diagnosis of Clonorchis sinensis, and implication for assessing drug efficacy. Parasites \& Vectors, 2013. 6. 
49. da Frota, S.M., et al., Combination of Kato-Katz faecal examinations and ELISA to improve accuracy of diagnosis of intestinal schistosomiasis in a low-endemic setting in Brazil. Acta Tropica, 2011. 120: p. S138-S141.

50. Jurberg, A.D., et al., A new miracidia hatching device for diagnosing schistosomiasis. Memorias Do Instituto Oswaldo Cruz, 2008. 103(1): p. 112-114.

51. Karl, S., et al., The Iron Distribution and Magnetic Properties of Schistosome Eggshells: Implications for Improved Diagnostics. Plos Neglected Tropical Diseases, 2013. 7(5).

52. WHO, The control of schistosomiasis : second report of the WHO Expert Committee [meeting held in Geneva from 8-15 November 1991]. 1991.

53. Pontes, L.A., et al., Comparison of a polymerase chain reaction and the Kato-Katz technique for diagnosing infection with Schistosoma mansoni. American Journal of Tropical Medicine and Hygiene, 2003. 68(6): p. 652-656.

54. Deelder, A.M., et al., Sensitive Determination of Circulating Anodic Antigen in SchistosomaMansoni Infected Individuals by an Enzyme-Linked Immunosorbent-Assay Using MonoclonalAntibodies. American Journal of Tropical Medicine and Hygiene, 1989. 40(3): p. 268-272.

55. Deelder, A.M., et al., Quantitative-Determination of Circulating Antigens in Human Schistosomiasis Mansoni Using an Indirect Hemagglutination Assay. American Journal of Tropical Medicine and Hygiene, 1989. 40(1): p. 50-54.

56. Deelder, A.M., et al., Recognition of Gut-Associated Antigens by Immunoglobulin-M in the Indirect Fluorescent-Antibody Test for Schistosomiasis Mansoni. Transactions of the Royal Society of Tropical Medicine and Hygiene, 1989. 83(3): p. 364-367.

57. Dejonge, N., O.C. Boerman, and A.M. Deelder, Time-Resolved Immunofluorometric Assay (Tr-Ifma) for the Detection of the Schistosome Circulating Anodic Antigen. Transactions of the Royal Society of Tropical Medicine and Hygiene, 1989. 83(5): p. 659-663.

58. Dejonge, N., et al., Circulating Anodic Antigen Levels in Serum before and after Chemotherapy with Praziquantel in Schistosomiasis Mansoni. Transactions of the Royal Society of Tropical Medicine and Hygiene, 1989. 83(3): p. 368-372.

59. Dejonge, N., et al., Presence of the Schistosome Circulating Anodic Antigen (Caa) in Urine of Patients with Schistosoma-Mansoni or S-Haematobium Infections. American Journal of Tropical Medicine and Hygiene, 1989. 41(5): p. 563-569.

60. Dejonge, N., et al., Presence of Circulating Anodic Antigen in Serum of SchistosomaIntercalatum-Infected Patients from Gabon. Acta Tropica, 1989. 46(2): p. 115-120.

61. Dejonge, N., Detection of the Circulating Anodic Antigen for Immunodiagnosis of Schistosoma Infections. Immunodiagnostic Approaches in Schistosomiasis, 1992: p. 111-124.

62. Gundersen, S.G., et al., Quantitative Detection of Schistosomal Circulating Anodic Antigen by a Magnetic Bead Antigen Capture Enzyme-Linked-Immunosorbent-Assay (Mbac-Eia) before and after Mass Chemotherapy. Transactions of the Royal Society of Tropical Medicine and Hygiene, 1992. 86(2): p. 175-178.

63. Shaker, Z.A., et al., Detection of Circulating Anodic Antigen before and after Specific Chemotherapy in Experimental Murine Schistosomiasis-Mansoni. International Journal of Immunopharmacology, 1992. 14(2): p. 151-158.

64. Vanlieshout, L., et al., Improved Diagnostic Performance of the Circulating Antigen-Assay in Human Schistosomiasis by Parallel Testing for Circulating Andodic and Cathodic Antigens in Serum and Urine. American Journal of Tropical Medicine and Hygiene, 1992. 47(4): p. 463-469.

65. Vantwout, A.B., et al., Schistosome Circulating Anodic Antigen in Serum of Individuals Infected with Schistosoma-Japonicum from the Philippines before and after Chemotherapy with Praziquantel. Trans. of the Royal Society of Tropical Medicine and Hygiene, 1992. 86(4): p. 410-413.

66. Cesari, I.M., Immunological Response in Schistosomiasis-Mansoni. Interciencia, 1990. 15(2): p. $76-85$.

67. Berggren, W.L. and T.H. Weller, Immunoelectrophoretic Demonstration of Specific Circulating Antigen in Animals Infected with Schistosoma Mansoni. American Journal of Tropical Medicine and Hygiene, 1967. 16(5): p. 606-\&.

68. Nash, T.E., Localization of Circulating Antigen within Gut of Schistosoma-Mansoni. American Journal of Tropical Medicine and Hygiene, 1974. 23(6): p. 1085-1087. 
69. Carlier, Y., D. Bout, and A. Capron, Further-Studies on the Circulating M Antigen in Human and Experimental Schistosoma-Mansoni Infections. Ann. D Immunologie, 1978. C129(6): p. 811-818.

70. Deelder, A.M., et al., Schistosoma-Mansoni - Characterization of 2 Circulating Polysaccharide Antigens and the Immunological Response to These Antigens in Mouse, Hamster, and Human Infections. Experimental Parasitology, 1980. 50(1): p. 16-32.

71. Feldmeier, H., et al., Detection and Quantification of Circulating Antigen in Schistosomiasis by Monoclonal-Antibody .2. The Quantification of Circulating Antigens in Human SchistosomiasisMansoni and Hematobium - Relationship to Intensity of Infection and Disease Status. Clinical and Experimental Immunology, 1986. 65(2): p. 232-243.

72. Sarhan, R.M., et al., Comparative analysis of the diagnostic performance of adult, cercarial and egg antigens assessed by ELISA, in the diagnosis of chronic human Schistosoma mansoni infection. Parasitology Research, 2014. 113(9): p. 3467-3476.

73. Gomes, L.I., M.J. Enk, and A. Rabello, Diagnosing schistosomiasis: where are we? Revista Da Sociedade Brasileira De Medicina Tropical, 2014. 47(1): p. 3-11.

74. Zhou, Y.B., H.M. Zheng, and Q.W. Jiang, A diagnostic challenge for schistosomiasis japonica in China: consequences on praziquantel-based morbidity control. Parasites \& Vectors, 2011. 4.

75. Colley, D.G., et al., A Five-Country Evaluation of a Point-of-Care Circulating Cathodic Antigen Urine Assay for the Prevalence of Schistosoma mansoni. American Journal of Tropical Medicine and Hygiene, 2013. 88(3): p. 426-432.

76. Bergquist, N.R., Immunodiagnosis of Schistosomiasis. Immunodiagnostic Approaches in Schistosomiasis, 1992: p. 1-8.

77. Bergquist, N.R., Present Aspects of Immunodiagnosis of Schistosomiasis. Memorias Do Instituto Oswaldo Cruz, 1992. 87: p. 29-38.

78. Grenfell, R.F.Q., et al., Innovative methodology for point-of-care circulating cathodic antigen with rapid urine concentration for use in the field for detecting low Schistosoma mansoni infection and for control of cure with high accuracy. Transactions of the Royal Society of Tropical Medicine and Hygiene, 2018. 112(1): p. 1-7.

79. Grenfell, R.F.Q., et al., Newly Established Monoclonal Antibody Diagnostic Assays for Schistosoma mansoni Direct Detection in Areas of Low Endemicity. Plos One, 2014. 9(1).

80. Moraes, V., et al., Antigens with the potential to differentiate between acute and chronic phases of Schistosoma mansoni. Faseb Journal, 2014. 28(1).

81. Corstjens, P.L.A.M., et al., Up-converting phosphor technology-based lateral flow assay for detection of Schistosoma circulating anodic antigen in serum. Journal of Clinical Microbiology, 2008. 46(1): p. 171-176.

82. Adriko, M., et al., Evaluation of circulating cathodic antigen (CCA) urine-cassette assay as a survey tool for Schistosoma mansoni in different transmission settings within Bugiri District, Uganda. Acta Tropica, 2014. 136: p. 50-57.

83. Standley, C.J., et al., Confirmed local endemicity and putative high transmission of Schistosoma mansoni in the Sesse Islands, Lake Victoria, Uganda. Parasites \& Vectors, 2011. 4.

84. Shane, H.L., et al., Evaluation of Urine CCA Assays for Detection of Schistosoma mansoni Infection in Western Kenya. Plos Neglected Tropical Diseases, 2011. 5(1).

85. Stothard, J.R., et al., Schistosoma mansoni Infections in Young Children: When Are Schistosome Antigens in Urine, Eggs in Stool and Antibodies to Eggs First Detectable? Plos Neglected Tropical Diseases, 2011. 5(1).

86. Diagnostics, R.M., Rapid diagnostic tests (RDT) for qualitative detection of Bilharzia (Schistosoma). Pamphlet. 2015.

87. Polman, K., et al., Epidemiologic Application of Circulating Antigen-Detection in a Recent Schistosoma-Mansoni Focus in Northern Senegal. American Journal of Tropical Medicine and Hygiene, 1995. 53(2): p. 152-157.

88. Vanlieshout, L., et al., Analysis of Worm Burden Variation in Human Schistosoma-Mansoni Infections by Determination of Serum Levels of Circulating Anodic Antigen and Circulating Cathodic Antigen. Journal of Infectious Diseases, 1995. 172(5): p. 1336-1342. 
89. Vantwout, A.B., et al., Serum Levels of Circulating Anodic Antigen and Circulating Cathodic Antigen Detected in Mice Infected with Schistosoma-Japonicum or Schistosoma-Mansoni. Parasitology Research, 1995. 81(5): p. 434-437.

90. Mutapi, F., et al., Differential recognition patterns of Schistosoma haematobium adult worm antigens by the human antibodies IgA, IgE, IgG1 and IgG4. Parasite Immunology, 2011. 33(3): p. 181192.

91. de Noya, B.A., et al., Detection of schistosomiasis cases in low-transmission areas based on coprologic and serologic criteria - The Venezuelan experience. Acta Tropica, 2007. 103(1): p. 41-49.

92. Bergquist, R., Prospects of Vaccination against Schistosomiasis. Scandinavian Journal of Infectious Diseases, 1990: p. 60-71.

93. Ferrari, T.C.A., P.R.R. Moreira, and A.S. Cunha, Clinical characterization of neuroschistosomiasis due to Schistosoma mansoni and its treatment. Acta Tropica, 2008. 108(2-3): p. 89-97.

94. Gentile, R., et al., Evaluation of immunological, parasitological and molecular methods for the diagnosis of Schistosoma mansoni infection before and after chemotherapy treatment with praziquantel in experimentally infected Nectomys squamipes. Veterinary Parasitology, 2011. 180(3-4): p. 243-249.

95. Grenfell, R.F.Q., et al., Schistosoma mansoni in a low-prevalence area in Brazil: the importance of additional methods for the diagnosis of hard-to-detect individual carriers by low-cost immunological assays. Memorias Do Instituto Oswaldo Cruz, 2013. 108(3): p. 328-334.

96. Ross, A.G.P., et al., Current concepts - Schistosomiasis. New England Journal of Medicine, 2002. 346(16): p. 1212-1220.

97. Mafe, M.A., et al., Control of urinary schistosomiasis: an investigation into the effective use of questionnaires to identify high-risk communities and individuals in Niger State, Nigeria. Tropical Medicine \& International Health, 2000. 5(1): p. 53-63.

98. Sheele, J.M., et al., Evaluation of a novel rapid diagnostic test for Schistosoma haematobium based on the detection of human immunoglobulins bound to filtered Schistosoma haematobium eggs. Tropical Medicine \& International Health, 2013. 18(4): p. 477-484.

99. Morenikeji, O., et al., A cross-sectional study on urogenital schistosomiasis in children; haematuria and proteinuria as diagnostic indicators in an endemic rural area of Nigeria. African Health Sciences, 2014. 14(2): p. 390-396.

100. Mharakurwa, S., et al., PCR detection of Plasmodium falciparum in human urine and saliva samples. Malaria Journal, 2006. 5.

101. Hamburger, J., et al., A polymerase chain reaction assay for detecting snails infected with bilharzia parasites (Schistosoma mansoni) from very early prepatency. American Journal of Tropical Medicine and Hygiene, 1998. 59(6): p. 872-876.

102. Hamburger, J., et al., Development and laboratory evaluation of a polymerase chain reaction for monitoring Schistosoma mansoni infestation of water. American Journal of Tropical Medicine and Hygiene, 1998. 59(3): p. 468-473.

103. Reithinger, R. and J.C. Dujardin, Molecular diagnosis of leishmaniasis: Current status and future applications. Journal of Clinical Microbiology, 2007. 45(1): p. 21-25.

104. Enk, M.J., G.O.E. Silva, and N.B. Rodrigues, Diagnostic Accuracy and Applicability of a PCR System for the Detection of Schistosoma mansoni DNA in Human Urine Samples from an Endemic Area. Plos One, 2012. 7(6).

105. Kjetland, E.F., et al., Schistosomiasis PCR in Vaginal Lavage as an Indicator of Genital Schistosoma haematobium Infection in Rural Zimbabwean Women. American Journal of Tropical Medicine and Hygiene, 2009. 81(6): p. 1050-1055.

106. Lier, T., et al., Real-time PCR for detection of low intensity Schistosoma japonicum infections in a pig model. Acta Tropica, 2008. 105(1): p. 74-80.

107. ten Hove, R.J., et al., Multiplex real-time PCR for the detection and quantification of Schistosoma mansoni and S-haematobium infection in stool samples collected in northern Senegal. Transactions of the Royal Society of Tropical Medicine and Hygiene, 2008. 102(2): p. 179-185.

108. Oliveira, L.M.A., et al., Evaluation of polymerase chain reaction as an additional tool for the diagnosis of low-intensity Schistosoma mansoni infection. Diagnostic Microbiology and Infectious Disease, 2010. 68(4): p. 416-421. 
109. Cnops, L., et al., Schistosoma real-time PCR as diagnostic tool for international travellers and migrants. Tropical Medicine \& International Health, 2012. 17(10): p. 1208-1216.

110. Gomes, L.I., et al., Development and Evaluation of a Sensitive PCR-ELISA System for Detection of Schistosoma Infection in Feces. Plos Neglected Tropical Diseases, 2010. 4(4).

111. Lodh, N., Diagnosis of Schistosoma mansoni without the Stool: Comparison of Three Diagnostic Tests to Detect Schiostosoma mansoni Infection from Filtered Urine in Zambia (vol 89, pg 46, 2013). American Journal of Tropical Medicine and Hygiene, 2013. 89(3): p. 608-608.

112. Lodh, N., et al., Diagnosis of Schistosoma mansoni without the Stool: Comparison of Three Diagnostic Tests to Detect Schiostosoma mansoni Infection from Filtered Urine in Zambia. American Journal of Tropical Medicine and Hygiene, 2013. 89(1): p. 46-50.

113. Wichmann, D., et al., Prospective European-wide multicentre study on a blood based real-time PCR for the diagnosis of acute schistosomiasis. Bmc Infectious Diseases, 2013. 13.

114. Obeng, B.B., et al., Application of a circulating-cathodic-antigen (CCA) strip test and real-time $\mathrm{PCR}$, in comparison with microscopy, for the detection of Schistosoma haematobium in urine samples from Ghana. Annals of Tropical Medicine and Parasitology, 2008. 102(7): p. 625-633.

115. Notomi, T., et al., Loop-mediated isothermal amplification of DNA. Nucleic Acids Research, 2000. 28(12).

116. Njiru, Z.K., Loop-Mediated Isothermal Amplification Technology: Towards Point of Care Diagnostics. Plos Neglected Tropical Diseases, 2012. 6(6).

117. Kaneko, H., et al., Tolerance of loop-mediated isothermal amplification to a culture medium and biological substances. Journal of Biochemical and Biophysical Methods, 2007. 70(3): p. 499-501.

118. Hamburger, J., et al., Evaluation of Loop-Mediated Isothermal Amplification Suitable for Molecular Monitoring of Schistosome-Infected Snails in Field Laboratories. American Journal of Tropical Medicine and Hygiene, 2013. 88(2): p. 344-351.

119. Mori, Y. and T. Notomi, Loop-mediated isothermal amplification (LAMP): a rapid, accurate, and cost-effective diagnostic method for infectious diseases. Journal of Infection and Chemotherapy, 2009. 15(2): p. 62-69.

120. Wang, C., et al., Application of DNA-based diagnostics in detection of schistosomal DNA in early infection and after drug treatment. Parasites \& Vectors, 2011. 4.

121. $\mathrm{Xu}, \mathrm{J}$., et al., Sensitive and rapid detection of Schistosoma japonicum DNA by loop-mediated isothermal amplification (LAMP). International Journal for Parasitology, 2010. 40(3): p. 327-331.

122. Lee, W.B., et al., A Magnetic-bead Based Microfluidic System for Automatic C-reactive protein Detection. Mnhmt2009, Vol 1, 2010: p. 257-260.

123. Martinez, A.W., et al., Diagnostics for the Developing World: Microfluidic Paper-Based Analytical Devices. Analytical Chemistry, 2010. 82(1): p. 3-10.

124. Dittrich, P.S. and A. Manz, Lab-on-a-chip: microfluidics in drug discovery. Nature Reviews Drug Discovery, 2006. 5(3): p. 210-218.

125. Lee, D.W. and Y.H. Cho, High-radix microfluidic multiplexer with pressure valves of different thresholds. Lab on a Chip, 2009. 9(12): p. 1681-1686.

126. Lee, H.L., et al., A Multi-Layered Microfluidic Device for Magnetophoretic Cell Separation. Biodevices 2009: Proceedings of the International Conference on Biomedical Electronics and Devices, 2009: p. 286-289.

127. Lee, S.H., et al., Effective mixing in a microfluidic chip using magnetic particles. Lab on a Chip, 2009. 9(3): p. 479-482.

128. Li, C.Y., et al., Rapid nanoliter DNA hybridization based on reciprocating flow on a compact disk microfluidic device. Analytica Chimica Acta, 2009. 640(1-2): p. 93-99.

129. Song, J.Z., et al., Molecular Detection of Schistosome Infections with a Disposable Microfluidic Cassette. Plos Neglected Tropical Diseases, 2015. 9(12).

130. Xiao, Y., et al., A Microfiltration Device for Urogenital Schistosomiasis Diagnostics. Plos One, 2016. 11(4).

131. Ishii, S., T. Segawa, and S. Okabe, Simultaneous Quantification of Multiple Food- and Waterborne Pathogens by Use of Microfluidic Quantitative PCR. Applied and Environmental Microbiology, 2013. 79(9): p. 2891-2898. 
132. Ribeiro, D.A., et al., Expression Profiling of Cell Cycle Regulatory Proteins in Oropharyngeal Carcinomas Using Tissue Microarrays. In Vivo, 2010. 24(3): p. 315-320.

133. Huyghe, A., P. Francois, and J. Schrenzel, Characterization of microbial pathogens by DNA microarrays. Infection Genetics and Evolution, 2009. 9(5): p. 987-995.

134. Young, N.D., et al., Whole-genome sequence of Schistosoma haematobium. Nature Genetics, 2012. 44(2): p. 221-225.

135. Walker, A.J., Insights into the functional biology of schistosomes. Parasites \& Vectors, 2011. 4.

136. Driguez, P., et al., Schistosomiasis vaccine discovery using immunomics. Parasites \& Vectors, 2010. 3

137. McWilliam, H.E.G., et al., Novel immunomic technologies for schistosome vaccine development. Parasite Immunology, 2012. 34(5): p. 276-284.

138. McWilliam, H.E.G., et al., Discovery of novel Schistosoma japonicum antigens using a targeted protein microarray approach. Parasites \& Vectors, 2014. 7.

139. Wu, Y.Q., et al., Diagnosis, Monitoring, and Control of Schistosomiasis-An Update. Journal of Biomedical Nanotechnology, 2018. 14(3): p. 430-455.

140. Liu, G.D., et al., Renewable amperometric immunosensor for Schistosoma japonium antibody assay. Anal Chem, 2001. 73(14): p. 3219-26.

141. Liu, D. and W. Jin, Amperometric detection of perphenazine at a carbon fiber micro-disk bundle electrode by capillary zone electrophoresis. J Chromatogr B Analyt Technol Biomed Life Sci, 2003. 789(2): p. 411-5.

142. Santos, G.S., et al., Impedimetric nanostructured genosensor for detection of schistosomiasis in cerebrospinal fluid and serum samples. J Pharm Biomed Anal, 2017. 137: p. 163-169.

143. Weerakoon, K.G., C.A. Gordon, and D.P. McManus, DNA Diagnostics for Schistosomiasis Control. Trop Med Infect Dis, 2018. 3(3).

144. Gryseels, B., et al., Human schistosomiasis. Lancet, 2006. 368(9541): p. 1106-1118.

145. Beck, L., et al., Discriminating acute from chronic human schistosomiasis mansoni. Acta Tropica, 2008. 108(2-3): p. 229-233.

146. Koukounari, A., et al., Sensitivities and Specificities of Diagnostic Tests and Infection Prevalence of Schistosoma haematobium Estimated from Data on Adults in Villages Northwest of Accra, Ghana. American Journal of Tropical Medicine and Hygiene, 2009. 80(3): p. 435-441.

147. Ajibola, O., et al., Tools for Detection of Schistosomiasis in Resource Limited Settings. Med Sci (Basel), 2018. 6(2).

148. Mabey, D., et al., Diagnostics for the developing world. Nature Reviews Microbiology, 2004. 2(3): p. 231-240.

149. Gray, D.J., et al., CLINICAL REVIEW Diagnosis and management of schistosomiasis. British Medical Journal, 2011. 342.

150. Friedrich, F., Morozov, O. and Hunziker, P., 2016, August. A compute model for generating high performance computing SoCs on hybrid systems with FPGAs. In FSP 2016; Third International Workshop on FPGAs for Software Programmers (pp. 1-12). VDE.

151. Stothard, J.R., Nabatte, B., Sousa-Figueiredo, J.C. and Kabatereine, N.B., 2014. Towards malaria microscopy at the point-of-contact: an assessment of the diagnostic performance of the Newton Nm1 microscope in Uganda. Parasitology, 141(14), pp.1819-1825.

152. Hayashida, K., Kajino, K., Hachaambwa, L., Namangala, B. and Sugimoto, C., 2015. Direct blood dry LAMP: a rapid, stable, and easy diagnostic tool for Human African Trypanosomiasis. PLoS neglected tropical diseases, 9(3), p.e0003578. 